International Journal of Linguistics, Literature and Culture
Available online at https://sloap.org/journals/index.php/ijllc/
Vol. 5, No. 6, November 2019, pages: 78 91
$\begin{aligned} & \text { ISSN: 2455-8028 } \\ & \text { https://doi.org/10.21744/ijllc.v5n6.772 }\end{aligned}$

\title{
Video-Based Observation in Master Chef Role-Plays
}

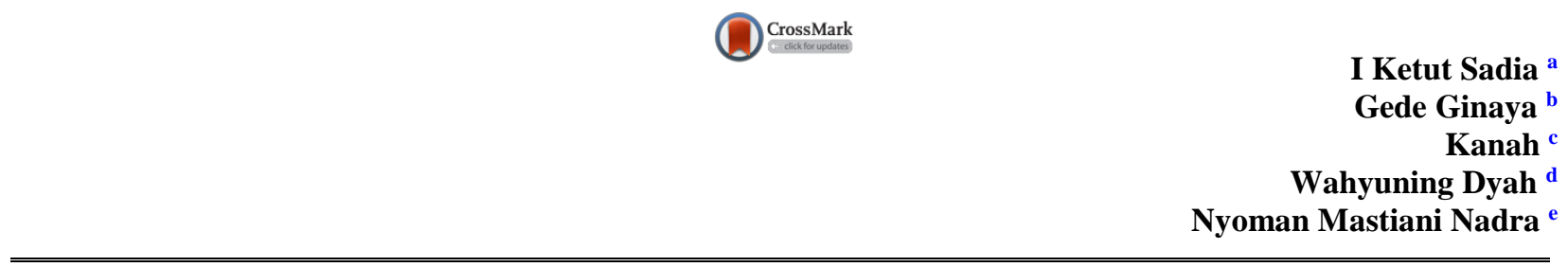

Article history:

Received: 27 May 2019

Accepted: 30 September 2019

Published: 26 October 2019

\author{
Keywords: \\ role-plays; \\ speaking ability; \\ video recording; \\ vocation; \\ atmosphere;
}

\begin{abstract}
The $21^{\text {st }}$ century has witnessed significant changes in the context of language teaching or learning as the world is increasingly globalized and digitalized. Therefore, students in vocational colleges are demanded to learn the skills to be able to survive and succeed in today's world as both a local and global citizen. The objective of this study was to implement the role-plays' technique of video recording to improve the student's speaking ability. In conducting the research, there were two components expected to be improved, namely the teaching-learning process to be conducive and the students' speaking scores. By applying classroom action research, data were collected in two cycles of learning. The result of the speaking test revealed that the students had made some progress, which was shown by the increase of students' average speaking scores. The improvement of the scores was also followed by the increase of students learning interest and motivation in a conducive teaching-learning atmosphere.
\end{abstract}

2455-8028 ${ }^{\circledR}$ Copyright 2019. The Author. This is an open-access article under the CC BY-SA license (https://creativecommons.org/licenses/by-sa/4.0/) All rights reserved.

\section{Author correspondence:}

I Ketut Sadia,

Politeknik Negeri Bali, Denpasar, Indonesia

Email address: ketutsadia@pnb.ac.id

\section{Introduction}

Video in smartphone application is a simple tool that enables teachers to easily film their classes. Using video in the class has been utilized which is terms as VEO or video enhanced-observation. Batlle \& Miller (2017), conducted a study about the perceptions of lecturers about VEO as a tool to observe peers in-service teachers in Spanish. This study was positive feedback where the teachers felt that VEO improved the process of peer observation. The

a Politeknik Negeri Bali, Denpasar, Indonesia

${ }^{\mathrm{b}}$ Politeknik Negeri Bali, Denpasar, Indonesia

${ }^{c}$ Politeknik Negeri Bali, Denpasar, Indonesia

${ }^{\mathrm{d}}$ Politeknik Negeri Bali, Denpasar, Indonesia

${ }^{\text {e }}$ Politeknik Negeri Bali, Denpasar, Indonesia 
improvement is that by allowing them to focus quickly and efficiently on special features in their classrooms where the exercise was marked by observations from their peers. In addition, this method made less time wasted in postlesson discussions in describing what actually happened in class, because the recorded video provides clear evidence.

The existence of social media, such as YouTube, Facebook, and WhatsApp allow teachers to observe practice videos teaching peers online, and to provide feedback and comments in a safe online environment, without meeting with others. However, there may be rejection among participating lecturers and education management to use video annotation tools for the analysis of pre-service teacher practice classes because the time required for annotations, tool costs, and comparative convenience with guided viewing tasks can be arranged and managed (Fadde \& Sullivan, 2013; Çelik et al., 2018; Ginaya et al., 2018; Shih, 2010; Rodríguez, 2016; Djahimo et al., 2018). Research on the use of video tools such as IRIS Connect and VEO recently began in the field of English lecturer education, and it is hoped that a study can be carried out at the Bali State Polytechnic.

Speaking skills in second language learning are highly required as a productive skill for communication. Speaking is involving almost all language components, such as pronunciation, vocabulary, grammar, and function. This productive skill is taught for the sake of lingua franca among people of different geographical background and it is better to master it in groups (Gaudin \& Chaliès, 2015; Gerich \& Schmitz, 2016; Borko et al., 2011; Koellner \& Jacobs, 2015). Fluency in speaking is the primary focus without ignoring accuracy. Ginaya (2018), stated that in practicing speaking in English, students are given a wide range of using their English for communication through practices and communicative activities. Those practices and activities are specially designed to stimulate students' active learning. One of the techniques used to facilitate them is role-playing. In line with the role-play technique social and cultural contexts are considered to be the most important factors about language (Zhang et al., 2011; Blomberg et al., 2013; van Es et al., 2014; van Es, 2012; Santagata \& Guarino, 2011; Nehe et al., 2018). In this case, culture has wide-variety elements. Therefore, teachers require to teach the language integrated with culture through some types of activities (Gröschner et al., 2014). Role-plays can fulfill the criteria of successful speaking activities of lots of speaking, involving, clear outcome, challenging, and supported Ginaya (2018), since they stimulate real-life situation and allow them to act out what they would do in a real situation (Busy Teacher, n.d., para. 1).

Some teachers are lucky when their classroom is provided with moveable chairs and they are away from the traditional classroom design with heavy tables (McCaughey, 2018). The Centers for Disease Control and Prevention (2010) "found a positive association between classroom-based physical activity and indicators of cognitive skills and attitudes, academic behavior, and academic achievement." This statement clearly conveys that role-plays as live activities require students to be active during the speaking practice by utilizing the moveable chairs in the classroom. While students acquire foreign languages more easily and faster, they have a high spirit in achieving their language learning progress (Arshavskaya \& Whitney, 2014). Every student in learning English as a foreign language endeavor to master language skills (Seidel et al., 2011). The opportunity to speak requires innovative learning facilitation provided by teachers. The need for using language as a means of communication rather than talking about the language is preferable among students (Seidel et al., 2011). This method of learning is focused on fluency before the accuracy, which is able to help students' speaking abilities. Moreover, listening and reading as receptive skills can improve speaking skills because reading can affect the fluency and accuracy of expressions in their speech (Wang \& Cui, 2016). Learning to speak requires a lot of practice and requires speaking activities which are life and fun (Lee, 2016; Baecher \& Kung, 2011; Baecher \& Connor, 2016).

One of the most significant discussions at the time being for mastering speaking skills is to develop the ability of students in using English in the real situation through the teaching-learning process (Oliver \& Stallings, 2014; Ellis et al., 2015). Much attention has been given to speaking skills. However, there are several problems with communicative competence and oral assignment objectives. Therefore, the objective of this research is to provide interesting materials, fun activities, and procedures for readers to improve their speaking skills. Based on observations and interviews with department managers and lecturers in the Bali State Polytechnic Tourism Department, there are several problems in learning Foreign Languages for Tourism today, including 1) the learning model applied so far is still centered on a conventional methodological paradigm that is monotonous, beginning with lectures, then giving practice, and communicative activities. 2) Textbooks are still text-based learning with teaching materials that do not accommodate the current situation in the graduate user industry. 3) Students are still less motivated to learn. 4) The perception of Bali State Polytechnic Tourism Department students interviewed about learning English today also states that learning English in Tourism needs to integrate online learning with face-toface learning in the classroom. This method of learning aims to improve learning outcomes, such as more focused learning activities with clear instructions, facilitating independent learning and better timing, increasing learning involvement through social interaction, and realizing $60 \%$ of the portion of learning practices applied in vocational

Sadia, I. K., Ginaya, G., Kanah, K., Dyah, W., \& Nadra, N. M. (2019). Video-based observation in master chef roleplays. International Journal of Linguistics, Literature and Culture, 5(6), 78-91. https://doi.org/10.21744/ijllc.v5n6.772 
education. The learning model that emphasizes this process aims to improve students' language proficiency with an assessment principle that measures skills (proficiency test), which measures what can be done (what to do) and not what is known (what to know) so that students can develop critical thinking.

Based on the analysis of the above conditions, and reflecting on the communication skills of students in the Tourism Department, State Polytechnic of Bali. In addition, the inadequate teaching ability of foreign language instructors in vocational education institutions, research on video-based observation is needed to improve ability speaking, the accuracy and smoothness of the foreign language of the students. The endeavor of using technology in foreign language learning at the Tourism Department, Bali State Polytechnic, which can also develop the professionalism of foreign language lecturers in the department in English, Japanese, Mandarin, and Russian. This study aims to investigate the effectiveness of the implementation of video-based observation in role-plays of speaking activities. This method of teaching is based on the process which beneficial in improving students' speaking ability. Additionally, the students' speaking activities that were recorded through video are expected to motivate students in the speaking activities and enabled the teacher to assess the students' speaking achievements provided by the evidence of the recorded video.

\section{Materials and Methods}

This study employed classroom action research (CAR) that follows Kemmis' cycle process, which includes planning, implementing, observing, and reflecting (Kemmis et al., 2013). In the planning step, the researcher planned the action to answer the teaching problem, which causes the students' poor speaking ability; prepared the method, strategy, and technique of teaching, designed a lesson plan, provided media, made assessment sheet, and determined criteria of progress. In implementing step, researchers practiced the method, strategy, and technique of teaching. In the observing step, the researcher recorded and collected data related to events or information in the whole teachinglearning process. In reflecting step, researchers evaluated the result of the actions applied and drew the conclusion of whether there was any improvement in speaking ability performed by the students. The study was conducted at Hotel Study Program, Tourism Department, Bali State Polytechnic and the subject of the study were the second-semester students (2A class) in the 2018/2019 academic year. The number of the subject is 32 consists of 18 females and 14 males.

A preliminary observation was conducted before conducting the two-cycle of learning. The teaching method applied in this preliminary observation was the traditional one without designing the classroom into moveable chairs and desks for communicative activities so that the teaching method was tending to the teacher-centered through lecturing. At the end of the meeting session, a pre-test was administered and it was found the average score of 2.94. This score was considered to be low and the students also had low learning motivation and interest.

\section{Results and Discussions}

This part describes the research findings and discussion based on the analysis of the collected data derived from the implementation of role-play activities in the teaching of speaking at the second-semester students of Hotel Study Program, Tourism Department, Bali State Polytechnic. The data and findings of the study are presented based on the result of students' speaking tests, observation, and teaching diary. They are obtained from ten meetings of two cycles in the implementation of the role-play technique. This technique of teaching is adopted due to the problem faced by students in the preliminary observation where students' learning interest and motivation was low so that they did not achieve an optimum score in speaking.

\subsection{Findings of Data in Cycle 1}

This section presents the data found throughout cycle 1, which had 5 meetings. From the first to the fourth meeting, the researcher observed the implementation of the role-play activities. The speaking test was administered in the fifth meeting of the learning cycle. The researcher scored the students speaking skills using the rubric instruments. The presented data in this section is considered as the manifestation of the observation of the teaching and learning process in fourth meetings and the result of the students' speaking test of the cycle of learning. 
a) Teaching and Learning Process

The implementation of the action in cycle 1 was applied in five meetings, four meetings for the teaching-learning process and one meeting for the speaking test. In implementing the action, the researchers carried out the teachinglearning process in four stages, namely planning, action, observation, and reflection. Before implementing the action, the teacher prepared a lesson plan, teaching materials, and seat arrangement. The teacher made the lesson plan for each meeting containing the topics to learn and objectives of the instructional activities, procedures of conducting the learning, and the learning materials. Each meeting consisted of an introduction to the language used for certain situations in the role-play activities. The seat arrangement is very important in the success of role-play activities because the activities require live movements when the students act a certain character based on the situation given. Therefore, the seats should be reflecting the moveable class in order to manage more active and healthful lessons that support students' performances. In cycle 1, the stage was arranged in O model where the students sat in circular form in the center of the classroom and the teacher was in front of the students. This classroom design was hoped to maximize the students' performances through collaborative learning and to ease the observation. The class ran in a conducive atmosphere when the teacher came to the class. He gave the explanation about the teaching-learning process that the students would have, the focus of it is in the application of role-plays' speaking activities. The explanation of the application of it is very important to avoid misunderstanding of the students and to foster them on how to maximize the teaching strategy in improving their speaking ability.

The situations in which the students would perform in role-plays were prepared in the form of role cards. They would take and understand what situations were and tried to act them out in the class using all the language they knew with a little preparation. This was meant to induce spontaneity and encourage the role-plays. Materials of teaching were made in the context of food and beverage operation in line with the subject course taken by the second-semester students. In cycle 1, the researcher used media such as smart board, video camera, and role-play cards. The smartboard was used to explain speaking situations/topics they probably faced in a restaurant and kitchen and video camera was used to record their performances. In this case, video recording was also utilized to motivate the students in practicing the role plays and observe the students' speaking ability. Additionally, role-play cards were used to guide the students' performances in doing the role-plays. The teacher wrote some situation to be practice in role-plays in the role-play card, such as what does the chef do? What does the guest want? Would you prefer mixed vegetable or tomato?, etc. The first meeting was about the introduction to the implementation of food and beverage operation role-plays for the students. The meeting was done in three stages, namely the initial observation (preteaching), when the teaching in progress (whilst teaching), and at the end of teaching (post teaching). The first meeting had a goal to introduce the students how to perform the role-plays as well as to train them to play it. In the pre-teaching stage, the teacher warmed the speaking class by making conversation with some students for about 10 minutes. After the warming session, the teacher explained how to initiate, maintain, and develop conversations. He also gave an explanation about how to make comments and rejoinders.

The pre-teaching step was the step to develop students' knowledge about the lesson they were going to learn about. At this step, he also explained how to use that knowledge in the form of food and beverage operation roleplays. The next stage was introducing the role-plays. This stage was a training session in which students were encouraged to perform the role-plays as well as to introduce the technique so that they would get used to doing it. In this step, the students were asked to perform the role-plays, in which the chairs were arranged such away in the form of a circle. As this training stage was conducted in a small group of four or five students, there were different speaking topics/situations for each group. The first step was they got a role-play card for each one with the same topic for one group. The students could change the role card with another student in the same group, but it could not do with another group. Then, they had 5 minutes to prepare the role-plays based on the role they acted.

The teacher should be assigned the students in the group randomly, so there were high and low achiever students in each group. When the students had in a group, then the researcher distributed the role-play cards that will be used by the students. The speaking topics that could be played by the students were What does the chef do? What does the guest want?, Would you prefer mixed vegetable or tomato? To enhance students' motivation to use English in the performance, the researcher let them use English as much as possible. He did not interrupt or correct any mistakes made by the students. Otherwise, he told them to speak freely and loudly without worrying of any mistake they would make. Enhancing students' motivation was the most important key in succeeding in the implementation of role-play activities.

There were six groups performed role-plays in the first meeting of cycle 1. Because it was the first time they performed role-plays, there were many obstacles found, such as most of the students paused or broke their speaking, they were shy and hesitated to speak, they had no confidence, some students dominated conversations, and some

Sadia, I. K., Ginaya, G., Kanah, K., Dyah, W., \& Nadra, N. M. (2019). Video-based observation in master chef roleplays. International Journal of Linguistics, Literature and Culture, 5(6), 78-91. https://doi.org/10.21744/ijllc.v5n6.772 
students used their native language. There were two group performed the role-plays below the expected time allocation, it was under three minutes play. Many obstacles found in the first meeting, but overall, it was successful. They could do it; they could perform role-plays of food and beverage operation context. The teacher just believed it needed the time to practice for them to be better in their role-plays. The obstacles found would minimize next time. To enhance the students' speaking ability, the teacher told them to speak freely and not to worry of making mistakes in speaking English.

The second meeting has also consisted of six groups with similar teaching stages, such as began with preteaching, introducing the objectives and the learning material, followed by whilst teaching, and speaking activities in the form of role-plays and closed with post teaching by reviewing and having feedback. In the pre-teaching stage, the teacher used it to review the latest meeting performances, to explain the speaking lesson objectives in that day, and to motivate the students in doing the role-plays. They firstly study the role cards, made a brief preparation by discussing the roles with peers in their respective groups. They then acted and spoke using English and this time they performed without any help from the teacher. The situations they performed were opening and closing time, turning down requests, guests arriving at restaurant, and in the bar: what can I get you?

After receiving the role cards, they performed the role-plays group by group. They performed it by sitting or standing based on the situation of the speaking. They seemed to have better performances than the first time performance. The teacher found that the students were more relaxed in the role-plays this time. Some students were laughing, smiling, yelling, and speaking more loudly. There was also an increase of the performance time allocation. However, it still did not reach the time allocation. In spite of the improvement of the performance, there were also many obstacles of it. Some indications should be paid attention, such as some students still paused or broke their speaking, most of the students performed no solution in the role-plays, but it was quite alright. The most important thing was some students could handle their shyness and nervousness in the second session. The teacher also found that some students still dominated the conversations and they made many grammatical errors and vocabularies mispronounced. For some students, there were too many difficult roles. From this meeting, the researcher tried to do some reflection of the implementation of the role-plays. One of them is to simplify the topics of speaking. The motivation was very important to improve the quality of the teaching of speaking by using role-plays. Sharing with students was the other way to get the goal.

The third meeting of cycle 1 was conducted that started with dividing the students into six groups and then executed the teaching-learning process through pre-teaching, introducing the objectives and the learning material, whilst teaching, implementing speaking activities in the form of role-plays, and post-teaching, reviewing and having feedback. In the pre-teaching stage, the teacher reviewed the latest meeting performances, determined the strength and the weakness of the students' performances, explained the speaking lesson objectives in that day, and motivated the students to do role-play. When the students were ready to practice the role-plays, they started to perform some roles of speaking in the role cards. The topics of speaking were taking a food order, Explaining dessert menus, Talking about wine, Dealing with requests, and Describing dishes. The teacher gave the role cards and he explained the roles to the students. After 5 minutes of preparation of the role-play activities, then the students were ready to play. They had to play based on the role given and time allocation. There were many changes of the students' performances. They could play longer than before, even one group was still under the time allocation, but one group could reach the time allocated by the teacher. The great progress revealed in this meeting was most of the students were not getting embarrassed anymore. The use of their own native language was reduced, though two or three students still dominated speaking, in general, it was alright as it helped running the role-play activities. Another problem was two groups misunderstood the roles card given, but the performances this meeting was really better than previously. In order to make it better, sharing the idea of their obstacles would produce a positive impact as the evaluation to be better next performance.

The same step and procedure were done for the fourth meeting that started with pre-teaching, explaining the objectives and the learning material, whilst teaching, implementing speaking activities in the form of role-plays, and post-teaching, reviewing and having feedback. The teacher distributed the role cards and then the students performed role-plays based on the roles of speaking in the role cards. The topics were made in such a way to enhance the students' interaction in English. The topics of speaking were Dealing with complaints, jobs and workplaces, Explaining and instructing, Offering help and advice, and paying bill. The students got role cards, learned them, and made short preparation. They just had time not more than 5 minutes. Then, they had to play role-plays based on the role given and time allocation. They role-play activities were better in this meeting. They were happy doing the roleplays. They could reduce their shyness, hesitation, and nervousness. They liked 'real-life' problems. The reflection this time was keep motivating the students, tell them talk more freely, they needed more time to prepare 
improvisations, and it is important to correct their mistakes. At last in the fifth meeting was executed by administering the speaking test as the post-test of this cycle of learning (cycle 1). The speaking test was also in the form of role-play and the teacher would record the students' performance by the video camera in order to motivate students to perform optimally as well as observe their speaking ability with some aspects of language.

\section{b) The Result of the Students' Speaking Test}

The execution of this classroom action research was based on the teaching of speaking problems faced by the students of Hotel Study Program, Tourism Department, Bali State Polytechnic. The problems identified were the students were not confident to speak English because they always worried of making mistakes and their friends would laugh at them. Additionally, they were shy to speak English due to the lack of vocabulary and fluency, they hesitated to speak English because they thought that their English was not good enough, and they always thought about grammar as they worried if their speaking was not grammatically correct. Consequently, they would not speak English too much or frequently got silent. By implementing role-play activities, it was expected that those problems would be solved. In order to get the result of the implementation of the role-plays, the researchers conducted test in the end of cycle 1 . The test was speaking test where the steps of test were (1) grouping the students of six, (2) giving the topics of speaking to be performed in role-plays, (3) presenting the oral test, (4) scoring the students' speaking ability, and (5) recording the speaking test. There were some topics given in the speaking test, such as Customer information, Welcoming guests, Serving drinks, Foodservice, Complaints and apologies, Mistakes and problems, and Giving advice and assistance. The speaking aspects scored were including pronunciation, grammatical accuracy, vocabulary, the relevance of content or ideas, fluency, and manner of expression (confidence). The scales of the score were Excellent (5 marks), Very good (4 marks), Good (3 marks), Fair (2 marks), and Poor (1 marks). Based on the rating employed by the researchers in assessing the students' speaking performance, it was revealed that the students' average score was 3.08, the highest score was 4.32, and the lowest score of 2.00. In this area of score, the ability was qualified as 'good'. According to the rubric used for this assessment, the student with good quality has the characteristics as it is shown in table 1.

Table 1

The rubric of speaking test

\begin{tabular}{|c|c|c|c|c|c|}
\hline \multicolumn{6}{|c|}{ Aspects of Speaking } \\
\hline Pronunciation & Grammar & Vocabulary & Content/Ideas & Fluency & $\begin{array}{l}\text { Manner of } \\
\text { expression }\end{array}$ \\
\hline $\begin{array}{l}\text { A few words } \\
\text { are incorrectly } \\
\text { pronounced } \\
\text { but meaning is } \\
\text { not affected }\end{array}$ & $\begin{array}{l}\text { One or two } \\
\text { major errors, } \\
\text { which affect } \\
\text { meaning }\end{array}$ & $\begin{array}{l}\text { Some content } \\
\text { words are } \\
\text { repeated a } \\
\text { number of } \\
\text { times. One or } \\
\text { two words are } \\
\text { not correctly } \\
\text { used }\end{array}$ & $\begin{array}{l}\text { Some ideas are } \\
\text { directly related } \\
\text { to the topic. } \\
\text { Others are } \\
\text { indirectly } \\
\text { related }\end{array}$ & $\begin{array}{l}\text { Hesitation is } \\
\text { shown in almost } \\
\text { every sentence }\end{array}$ & $\begin{array}{l}\text { Show some signs } \\
\text { of nervousness }\end{array}$ \\
\hline
\end{tabular}

Based on the result of the test, there was a slight improvement of students' average scores from the pre-test to the post-test in cycle 1 . The average pre-test score was 2.94 and the average score of the students' post-test was 3.10 . That means that there was $16 \%$ of average score improvement.

\section{c) The Result of Classroom Atmosphere Observation}

The classroom atmosphere observation concerned of two components, namely the students' participation, and the students' performances. The second-semester students (2A class) of Hotel Study Program, Tourism Department in 2018/2019 academic year studying English twice a week, Tuesday and Thursday at 08.00-1050. The participation of students were: 30 students $(93.75 \%)$ in the first meeting, 31 students $(96.88 \%)$ in the second meeting, 29 students $(90.63 \%)$ in the third meeting, 32 students $(100 \%)$ in the fourth meeting, and 32 students $(100 \%)$ in the fifth meeting. The average students' participation in the 4-meeting session of teaching-learning process was $95.32 \%$. The second component was about the students' performances. In the first meeting, most of the students could cooperate well in the role-play activities, half of them could respond their friends' speaking, but only few students who were able to

Sadia, I. K., Ginaya, G., Kanah, K., Dyah, W., \& Nadra, N. M. (2019). Video-based observation in master chef roleplays. International Journal of Linguistics, Literature and Culture, 5(6), 78-91. https://doi.org/10.21744/ijllc.v5n6.772 
ask and express spontaneously. In the second meeting most of the students could cooperate in the role-play activities, half of them could respond their friends' speaking and could ask about related topics, and still few students able to express spontaneously. In the third meeting all of the students could cooperate in the role-plays, most of them could respond to their friends' speaking, half of the students could ask, and only few students who could express spontaneously. In the fourth meeting, all of the students could cooperate in the role-plays; most of them could ask and respond to their friends' speaking, but still, only a few students who were able to express spontaneously when they were speaking English.

\section{d) Reflection of Cycle 1}

As presented in the data findings of cycle 1, the implementation of the role-plays gave a significant effect on the students' speaking ability. They were able to make role-play activities with the situation given. They could reduce their anxiety, hesitation, and worry of making mistakes. They could make and arrange the role-play situation with an improvisation using their own knowledge. They also could initiate, maintain, and develop conversation using their imagination. However, there were still some weaknesses in their performances. In the first and second meetings, the researcher found some unsatisfactory results of the implementation of role-play activities. Some groups could not reach the time expected. Some students dominated conversations. Several acts were not in accordance with the situation in the role cards. Some students still felt embarrassed and sometimes nervous and this situation forced them to switch the code into their own native language. They also often committed grammatical errors and mistakes in pronouncing certain words. Those drawbacks were regarded as common things at the beginning of role-play activities. In fact, it was not easy for them to act certain characters spontaneously and make an improvisation of the acting they should play.

In the third and the forth meeting, most of the students did not get shy and nervous anymore, instead they were able to reduce the use of their native language, and they could reduce their grammatical mistakes and pronunciation. They also could manage the time. In addition, the most important was they were happy in doing role-plays right then. The implementation of the research was expected to improve students' speaking ability and to improve the class atmosphere of teaching-learning process. The aspect of the students' speaking performance was impressive but it still needed improvement. In the aspect of classroom atmosphere also rapidly changed into a conducive one. Their average participation was categorized high, 95.32\%. Their participation in the role-plays was also observed by focusing on their cooperation, asking, responding, and spontaneous expression. In the first cycle, there were still few students did not respond and express spontaneously in the performances. From the speaking score, the implementation of role-play activities in the first cycle was successfully done. This progress was also followed in the classroom atmosphere. A better plan should be followed up in the next learning cycle in order to eliminate the drawbacks found in the first cycle.

\subsection{Data Findings of Cycle 2}

The presentation in this section was the data found throughout cycle 2. Similar to cycle 1 , this cycle also had five meetings where the speaking test was administered in the fifth meeting. The researchers scored the students speaking ability using the score sheet instruments from the speaking rubric and the teaching diary.

\section{a) Teaching and Learning Process}

The implementation of the action in cycle 2 was also applied in five meetings, four meetings teaching-learning process and one meeting for speaking test. The teaching of speaking using improvisations in cycle 2 was applied based on the lesson plan made before. There were differences in using the materials of teaching and seat arrangement. In cycle 2, the researcher used more real objects as teaching materials such as: photos, food menus and drink lists, and restaurant bills. In cycle 2, the stage was also arranged in circular form (O), which is placed in the center of classroom. However, the teacher was not in front of the students, instead he was joined with students. In this cycle, the teacher utilized media such as, smart board, video camera from the smartphone, speaking aids (photos, food menus and drink lists, and restaurant bills), and role-play cards. Video camera was used to record their activities and to encourage them in acting. The role-play cards were chosen mostly about the real life of food and beverage operation in a restaurant, which is in accordance with the subject course they learned in the second semester. The first meeting was about the introduction to the implementation of role-play activities for the students. The meeting was done in three stages, the pre-teaching, whilst teaching, and the post teaching. 
The goal of the first meeting was to introduce the students how to perform role-play activities with some modification and improvement. In the pre-teaching stage, the teacher initiated to do warming up the speaking class by asking students to do a group discussion about 10 minutes. After the warming up session, the teacher explained how to use the language expressions and some structures to practice. In the role-play activities, the students would do it in the same way like the first cycle but there were several additional changes they would do. There would be different speaking topics/situations but it was more real situation in the context food and beverage operation for each group. The first step was they would get a role-play card for each one with the same topic for one group. The researcher also distributed some teaching aids such as photos, food menus and drink lists, and restaurant bills depend on their topics of speaking. In order to enhance students' motivation to use English in the role-plays, the teacher asked them to use the teaching aids by standing, sitting, or walking as the students could do free movement in such moveable chairs. He also instructed the students to use their feelings, such as emotion; laugh, smile, anger, or sad. He told them to speak freely and loudly without worrying of any mistakes the student would make. The teacher also prepared the students report that was used by other students who did not perform in front of the class to write the role-play activities by other groups. The goal was to get the attention of other groups as well as to involve all the students in the speaking class. All groups performed longer role-plays although there was one group under the time allocation given. At the end of the lesson, there was a discussion about the performances in that meeting session. The teacher discussed and corrected some grammatical errors and mispronounced words made by the students. He also gave some constructive comments and suggestions to the students, which focused on the use of teaching aids, time management, maximizing the properties, and the use of body language and eyes' contact.

The second meeting was conducted with the same step from the first session, such as beginning from pre teaching, introducing the objectives and the learning material, followed by whilst teaching; speaking activities in the form of role-play activities and closed with post teaching by reviewing and having feedback. In the pre-teaching, it was focusing on reviewing the last performance and motivating students on how to make their speaking better through the role-play activities. They performed it by sitting, standing, or walking around the class based on the situation of the speaking and the characters they should act. They also used their spontaneous expression and body language. Most of the students could reduce the fear of making mistakes. They also could reduce their grammatical errors and mistakes in pronouncing words. They seemed enjoying the role-play activities. While other students listened and paid attention to the performances as well as wrote a report. The teacher found the performances of the students getting some progresses. The same step of teaching speaking of third meeting was done; pre-teaching, introducing the objectives and the learning material, whilst teaching, implementing speaking activities in the form of role-play activities, and post-teaching, reviewing and having feedback. In the pre-teaching stage, the researcher reviewed the latest meeting performances and, motivated them in order to make the role-play activities better. There were six groups performed in the third meeting. They performed some role-plays in the role cards prepared before. This time, they were able to show a good performance from the all aspects. From the time allotment, the students could manage the time well. They all performed over the time allocation, 3 minutes. They were happy; smiling and laughing. They used all area of the classroom; sitting, walking, and standing. They could maximize the properties; chairs, table, bag, mobile phones, and other teaching aids. Additionally, they expressed their emotional feelings and body language.

The fourth meeting was applied with the same step as the previous teaching speaking, such as pre-teaching, explaining the objectives and the learning material, whilst teaching, implementing speaking activities in the form of role-plays, and post-teaching, reviewing and giving feedback. There were also six groups performed in the fourth meeting. They performed role-plays based on the roles of speaking in the role cards, which were about a reality show entitled Master Chef, a TV cooking competition. The procedure of the role-play as it is shown in table 2.

Table 2

The Procedure of Master Chef Role-plays

\begin{tabular}{lll}
\hline \multirow{2}{*}{ Procedure } & \multicolumn{2}{c}{ Roles } \\
\cline { 2 - 3 } & Judges & Chefs \\
\hline Work in groups of four. & $\begin{array}{l}\text { Make a list of three } \\
\text { Two students are the }\end{array}$ & $\begin{array}{l}\text { Think of a recipe using } \\
\text { judges. Two students are } \\
\text { the chefs. }\end{array}$ \\
$\begin{array}{l}\text { to use. You will decide } \\
\text { which chef creates the } \\
\text { best recipe. }\end{array}$ & $\begin{array}{l}\text { Name the recipe and how } \\
\text { to make it. }\end{array}$ \\
\hline
\end{tabular}

Sadia, I. K., Ginaya, G., Kanah, K., Dyah, W., \& Nadra, N. M. (2019). Video-based observation in master chef roleplays. International Journal of Linguistics, Literature and Culture, 5(6), 78-91. https://doi.org/10.21744/ijllc.v5n6.772 
The first step of implementing the role-play activities in the fourth meeting was they got a role-play card for each one with the same topic for one group. The teacher also handed some teaching aids such as photos, food menus, and drink list. Then, they had 10 minutes to prepare the role-plays by practicing the situation based on their own knowledge before performing. From this meeting, the researcher found that the interesting roles and the appropriate instruction, and the feedback given were really useful in succeeding the role-plays. This meeting, the students could perform the role-plays using the time allocation. Most of the students could speak English fluently. They could speak English freely without being afraid of making mistakes. Their vocabulary, pronunciation, and accuracy increased.

\section{b) The Result of Students' Speaking Test}

After doing the 4 sessions of meeting, then a speaking test was administered in order to obtain the result of the implementation of role-play activities in cycle 2. The steps of test were (1) grouping the students of three, (2) giving the topics of speaking to be performed, the topics were Taking restaurant bookings, Giving polite explanations, receiving guests, serving in the bar, Instruction of making a cocktail, Describing dishes, Dealing with complaints, Payment queries, (3) conducting the test by recording in video, and (4) scoring the students' speaking ability. The aspects of speaking to be scored were including pronunciation, grammatical accuracy, vocabulary, the relevance of content or ideas, fluency, and manner of expression. Based on the result of the test, there was slight improvement of students' average scores from the first test to the second test. The average first post-test score was 3.10 and the average score of the students' second post-test was 3.29. That means that there was $35 \%$ of average score improvement.

\section{c) The Result of Classroom Atmosphere Observation}

The observation focused on two components, namely the students' participation and the students' performances. The participation of students in cycle 2 were 32 students $(100 \%)$ in the first meeting, 30 students $(93.75 \%)$ in the second meeting, 31 students $(96.88 \%)$ in the third meeting, 31 students $(96.88 \%)$ in the fourth meeting, and 32 students $(100 \%)$ in the fifth meeting. The average was $96.88 \%$. The second component was the students' performances. In the first meeting most of the students could cooperate well in the role-plays and could respond their friends' speaking, most of the students were able to ask, and half of the students could express spontaneously. In the second meeting, most of the students could cooperate in the role-play activities, could respond their friends' speaking, and could ask about related topics, and still half of students able to express spontaneously. In the third and the fourth meeting, all of the students could cooperate in the role-plays, could ask, and respond to their friends' speaking, and most of them were able to express their ideas spontaneously. Overall, students could utilize the classroom design with moveable chairs in the form of $\mathrm{O}$ where they can work in circular form. This classroom design is regarded as a moveable class, which is in contrary with the traditional class as it is shown in table 3.

Table 3

Role-plays require moveable class

\begin{tabular}{ll}
\hline Role-play Moveable Class & Traditional Class \\
\hline $\begin{array}{l}\text { Students can sit down, stand up, walk in practicing role- } \\
\text { plays }\end{array}$ & Students only sit throughout the entire class period \\
$\begin{array}{ll}\text { Role-play activities required lots of movement can create } \\
\text { fun and live learning opportunities }\end{array}$ & $\begin{array}{l}\text { Students are limited in doing movement while } \\
\text { learning }\end{array}$ \\
$\begin{array}{l}\text { Role-play activities characterized by incorporate } \\
\text { movement }\end{array}$ & Students are doing desk-based activities only \\
$\begin{array}{ll}\text { Teachers and students enable to design the classroom } \\
\text { setting by arranging the moveable chairs, desks or tables }\end{array}$ & $\begin{array}{l}\text { Teachers and students have to accept the classroom } \\
\text { atmosphere with unmovable chairs and desks }\end{array}$ \\
\hline
\end{tabular}

\section{d) Reflection of Cycle 2}

The implementation of role-play activities had a significant impact in developing students' speaking ability. Based on findings taken from the observations, teaching diary, and the result of assessments of cycle 2 , it was finally concluded that the implementation of role-plays in the teaching-learning process had already shown some improvements. In cycle 2, the researcher made some adjustments of the implementation of role-play activity based on the reflection of cycle 1 . The researcher simplified the topics in the role-cards and developed real-life situations. He gave more time for students to prepare the role-plays and gave time to do practicing. He developed a student's 
report, so that the students paid attention to the performing and they wrote the result of other groups' performances. The researcher prepared speaking aids such as photos, food menus, and drink list, restaurant bills and asked the student to do role-plays by using those speaking aids. He asked students to do role-plays by sitting, standing, walking, and using their body language and use the students' emotions in performing such as angry, sad, happy, or curious. He also corrected grammatical errors and mispronounced words made by the students. Then he motivated students to speak more freely and never worry of making mistakes. The modification of the implementation brought a huge positive effect. By simplifying the topics close to their "real-life' problems in the context of food and beverage operation, they could do role-plays more vividly. By giving them more time to prepare, make them able to create more creative activities of role-plays. The student's report made them pay attention to the performances and increased their curiosity of the role-play activities.

Reporting the role-plays is also a way to practice their writing. Speaking aids, such as photos, food menus, and drink list, restaurant bills were really useful and helpful and made their performances more interesting. The positive impact of the modification of the implementation of role-plays in cycle 2 improved students' speaking ability. It was amazing when they were acting like the real actors/actresses; they expressed themselves freely by walking, standing, sitting, using body language, and doing vividly. Corrections to the students' mistakes improved their accuracy and pronunciation. Discussing the role-play acting was the key to make them create the performance more interesting, manage the time better, and perform better. Motivating them to speak English freely and not to worry of making mistakes made their confidence and fluency highly increased.

\section{Conclusion}

Based on the research findings, it is concluded that the role-play activities could improve the speaking ability of the students in Hotel Study Program, Tourism Department, Bali State Polytechnic. The students had high self-confidence to communicate their ideas when they were speaking English without being worried of making mistakes or their friends would laugh at them. In addition, they were not shy and did not hesitate when they communicated using English in role-play activities. Therefore, they like speaking English because they felt English was fun by applying role-play activities and utilizing video camera to record their performances. The result also revealed that the five criteria of successful speaking activities, such as lots of speaking, involving, clear outcomes, challenging, and supported had been reached. Therefore, the implementation of role-play activities had contributed two aspects of student outperformed by the implementation of role-plays in the teaching of speaking in the context of food and beverage operation, namely the conducive classroom atmosphere and the students' score improvement. The students had had made some progress, which was showed by the increase average students' speaking scores from 2.94 in the pre-test, 3.10 in cycle 1 and 3.29 in cycle 2. These scores indicated an increasing ability from being 'fair' to being 'good'. The classroom atmosphere were also increasing positively; the students were very actively involved in the teaching and learning process, indicated by $95.32 \%$ participated in cycle 1 and $96.88 \%$ participated in cycle 2 . The students were also highly motivated and had high learning interest during the teaching-learning process. These facts were revealed through cooperative and collaborative learning in asking and answering questions, responding to others, and expressing their ideas spontaneously. The design of a moveable classroom also contributed to the success of role-play activities. Additionally, video recording for their performances in every role-play activity had motivated them to perform better and the researchers to observe the students' performances for the purpose of either giving feedback to the students or scoring can use the video recording.

It is suggested that the teacher should be well prepared before teaching speaking using role-play activities. The teacher preparation will affect the implementation of role-plays themselves. The success on role-play activities is depending on how a teacher makes good preparation for some important elements of using role-plays. The videobased observation can be done by utilizing video camera from the smartphone and the recorded video can be shared to the students for learning feedback and enable to provide more time for the teacher to observe students' performances. Additionally, the role-play of master chef TV show can be done by students in group outside of class to let the students do their creativity. They can make the video with more real setting, such as they are cooking in a kitchen with the attire of a chef and using utensils and ingredients based on the recipe they make. Their own video then can be uploaded in social media like YouTube or Facebook.

Sadia, I. K., Ginaya, G., Kanah, K., Dyah, W., \& Nadra, N. M. (2019). Video-based observation in master chef roleplays. International Journal of Linguistics, Literature and Culture, 5(6), 78-91. https://doi.org/10.21744/ijllc.v5n6.772 
Conflict of interest statement

The authors declared that they have no competing interests.

Statement of authorship

The authors have a responsibility for the conception and design of the study. The authors have approved the final article.

\section{Acknowledgments}

The authors are very grateful to some parties who have given contributions and encouragements in completing this article. Particular thanks are owed to State Polytechnic of Bali who funded the authors' research, so thanks to the Director and the second-semester students of Hotel Study Program in 2019/2020 academic year. 


\section{References}

Arshavskaya, E., \& Whitney, A. E. (2014). Promoting pre-service second language (L2) teacher learning via narrative: A sociocultural perspective. Journal of Language Teaching and Research, 5(4), 731. https://doi.org/10.4304/j1tr.5.4.731-741

Baecher, L., \& Connor, D. (2016). Video as a tool in teacher learning. The New Educator, 12(1), 1-4. https://doi.org/10.1080/1547688X.2015.1066912

Baecher, L., \& Kung, S. C. (2011). Jumpstarting novice teachers' ability to analyze classroom video: Affordances of an online workshop. Journal of Digital Learning in Teacher Education,28(1), 16-26. https://doi.org/10.1080/21532974.2011.10784676

Batlle, J., \& Miller, P. (2017). Video enhanced observation and teacher development: teachers' beliefs as technology users. EDULEARN17 Proceedings, 2352-2361.

Blomberg, G., Renkl, A., Gamoran Sherin, M., Borko, H., \& Seidel, T. (2013). Five research-based heuristics for using video in pre-service teacher education. Journal for educational research online, 5(1), 90-114.

Borko, H., Koellner, K., Jacobs, J., \& Seago, N. (2011). Using video representations of teaching in practice-based professional development programs. ZDM, 43(1), 175-187. https://doi.org/10.1007/s11858-010-0302-5

Çelik, S., Baran, E., \& Sert, O. (2018). The affordances of mobile-app supported teacher observations for peer feedback. International Journal of Mobile and Blended Learning (IJMBL), 10(2), 36-49. https://doi.org/10.4018/IJMBL.2018040104

Djahimo, S., Bili Bora, D., \& Huan, E. (2018). Student anxiety and their speaking performance: teaching EFL to Indonesian student. International Journal of Social Sciences and Humanities, 2(3), 187-195. https://doi.org/10.29332/ijssh.v2n3.235

Ellis, J., McFadden, J., Anwar, T., \& Roehrig, G. (2015). Investigating the social interactions of beginning teachers using a video annotation tool. Contemporary Issues in Technology and Teacher Education, 15(3), 404-421.

Fadde, P., \& Sullivan, P. (2013). Using interactive video to develop pre-service teachers' classroom awareness. Contemporary Issues in Technology and Teacher Education, 13(2), 156-174.

Gaudin, C., \& Chaliès, S. (2015). Video viewing in teacher education and professional development: A literature review. Educational Research Review, 16, 41-67. https://doi.org/10.1016/j.edurev.2015.06.001

Gerich, M., \& Schmitz, B. (2016). Using Simulated Parent-Teacher Talks to Assess and Improve Prospective Teachers' Counseling Competence. Journal of Education and Learning, 5(2), 285-301.

Ginaya, G. (2018). The Balinese calendar system: From its epistemological perspective to axiological practices. International journal of linguistics, literature and culture, 4(3), 24-37.

Ginaya, G., Rejeki, I. N. M., \& Astuti, N. N. S. (2018). The effects of blended learning to students' speaking ability. International journal of linguistics, literature and culture, 4(3), 1-14.

Gröschner, A., Seidel, T., Pehmer, A. K., \& Kiemer, K. (2014). Facilitating collaborative teacher learning: the role of "mindfulness" in video-based teacher professional development programs. Gruppendynamik und Organisationsberatung, 45(3), 273-290. https://doi.org/10.1007/s11612-014-0248-0

Kemmis, S., McTaggart, R., \& Nixon, R. (2013). The action research planner: Doing critical participatory action research. Springer Science \& Business Media.

Koellner, K., \& Jacobs, J. (2015). Distinguishing models of professional development: The case of an adaptive model's impact on teachers' knowledge, instruction, and student achievement. Journal of Teacher Education, 66(1), 51-67. https://doi.org/10.1177\%2F0022487114549599

Lee, H. Y. H. (2016). English language learning in the margins: Toward a movement to help service-industry workers in Thailand. Theory and Practice in Language Studies, 6(4), 649-662. http://dx.doi.org/10.17507/tpls.0604.01

McCaughey, Kevin. (2018). The Movable Class: How to Class-Manage for More Active and Healthful Lessons. In English Teaching Forum (Vol. 56, No. 1, pp. 2-13). US Department of State. Bureau of Educational and Cultural Affairs, Office of English Language Programs, SA-5, 2200 C Street NW 4th Floor, Washington, DC 20037.

Nehe, B. M., Mayuni, I., \& Rahmat, A. (2018). Using sociodrama in EFL speaking class. International Journal of Linguistics, Literature and Culture, 4(4), 44-52. https://doi.org/10.21744/ijllc.v4n4.262

Oliver, K., \& Stallings, D. (2014). Preparing teachers for emerging blended learning environments. Journal of Technology and Teacher Education, 22(1), 57-81.

Sadia, I. K., Ginaya, G., Kanah, K., Dyah, W., \& Nadra, N. M. (2019). Video-based observation in master chef roleplays. International Journal of Linguistics, Literature and Culture, 5(6), 78-91. https://doi.org/10.21744/ijllc.v5n6.772 
Rodríguez, J. B. (2016). An interview with Paul Seedhouse on video enhanced observation (VEO): a new tool for teacher training, professional development and classroom research. Bellaterra Journal of Teaching \& Learning Language \& Literature, 9(3), 90-97.

Santagata, R., \& Guarino, J. (2011). Using video to teach future teachers to learn from teaching. Zdm, 43(1), 133145. https://doi.org/10.1007/s11858-010-0292-3

Seidel, T., Stürmer, K., Blomberg, G., Kobarg, M., \& Schwindt, K. (2011). Teacher learning from analysis of videotaped classroom situations: Does it make a difference whether teachers observe their own teaching or that of others?. Teaching and teacher education, 27(2), 259-267. https://doi.org/10.1016/j.tate.2010.08.009

Shih, R. C. (2010). Blended learning using video-based blogs: Public speaking for English as a second language students. Australasian Journal of Educational Technology, 26(6). https://doi.org/10.14742/ajet.1048

van Es, E. A. (2012). Examining the development of a teacher learning community: The case of a video club. Teaching and teacher education, 28(2), 182-192. https://doi.org/10.1016/j.tate.2011.09.005

van Es, E. A., Tunney, J., Goldsmith, L. T., \& Seago, N. (2014). A framework for the facilitation of teachers' analysis of video. Journal of Teacher Education, 65(4), 340-356. https://doi.org/10.1177\%2F0022487114534266

Wang, Z., \& Cui, Y. (2016). Mobile-assisted language learning in China's college English education: The reality and research. In Mobile learning design (pp. 335-349). Springer, Singapore. https://doi.org/10.1007/978-981-100027-0_20

Zhang, M., Lundeberg, M., Koehler, M. J., \& Eberhardt, J. (2011). Understanding affordances and challenges of three types of video for teacher professional development. Teaching and Teacher Education, 27(2), 454-462. https://doi.org/10.1016/j.tate.2010.09.015 


\section{Biography of Authors}

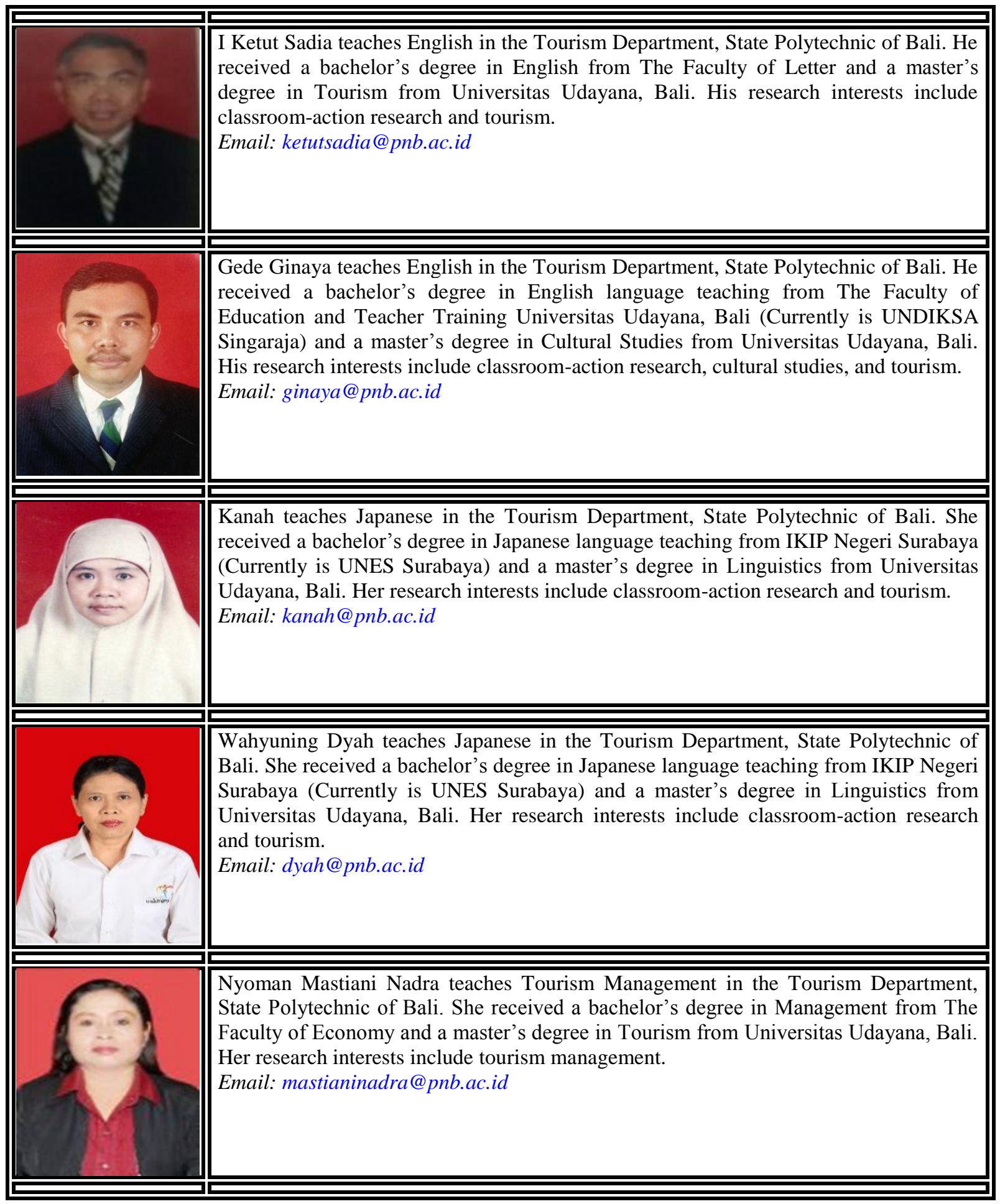

Sadia, I. K., Ginaya, G., Kanah, K., Dyah, W., \& Nadra, N. M. (2019). Video-based observation in master chef roleplays. International Journal of Linguistics, Literature and Culture, 5(6), 78-91. https://doi.org/10.21744/ijllc.v5n6.772 